\title{
Crafting Everyday Resistance through Lightweight Design
}

\section{Sarah E. Fox}

Carnegie Mellon University Pittsburgh, PA, USA sarahfox@cmu.edu

\section{ABSTRACT}

This pictorial examines the relationship between inquiry and activism within academic settings through the design of protest artifacts. Inspired by lineages of feminist print production, we illustrate our own process of creating simple acts of resistance through electronic posters and buttons. Naming these interventions "lightweight design interactions," we hold on to the ways design practice might work as modest, partial, and incremental shifts in the circumstances through which design futures unfold. Lightweight design interactions encourage us as design researchers to look beyond the bold creation of alternatives (new design artifacts) to the subtle nurturing of the circumstances that make alternatives possible.

Permission to make digital or hard copies of all or part of this work for personal or classroom use is granted without fee provided that copies are not made or distributed for profit or commercial advantage and that copies bear this notice and the full citation on the first page. Copyrights for components of this work owned by others than the author(s) must be honored. Abstracting with credit is permitted. To copy otherwise, or republish, to port on republish, to post on servers or to redistribute to lists, requires prior specific permission and/or a fee. Request permissions from Permissions@acm.org.

DIS '20, July 6-10, 2020, Eindhoven, Netherlands

C) 2020 Copyright is held by the owner/author(s).

Publication rights licensed to ACM.

ACM ISBN 978-1-4503-6974-9/20/07 ...\$15.00

https://doi.org/10.1145/3357236.3395571
Samantha Shorey

University of Texas at Austin

Austin, Texas, USA

sshorey@utexas.edu

\author{
Franchesca Spektor \\ Carnegie Mellon University \\ Pittsburgh, PA, USA \\ ebonancalagon@gmail.com
}

Daniela K. Rosner

University of Washington

Seattle WA, USA

dkrosner@uw.edu

\section{INTRODUCTION}

Over the past decade, an increasing number of designers are repurposing their skills toward activism [14]. Some refashion tech swag to call out the industry's complicity in climate change [12] and their efforts to block employees from unionizing [16]. Others develop large scale installations that call the public into discussion around issues of state violence and histories of dissent $[20,22]$. Yet, those of us who design are doing so knowing that holding up a sign or pinning on a badge may do little to challenge the patterns of domination we seek to unravel, such as patriarchy or white supremacy.

This pictorial uses the visual form of the "zine" to discuss the development of protest materials as they entwine with design practices. Zines are self-published magazines typically created using low-tech or widely available design tools. For more than a century, hand drawn and staple bound zines have been used by activists to share their ideas beyond the gatekeeping of professional publishing structures [3,5]. Previously, we have collaborated with artists to explore zinemaking as a method of communicating and formulating research findings with communities that might ordinarily act solely as field sites for academic researchers $[4,15]$.

Here, we turn to zines as a means to do research: exploring the labor of design that zines make visible and the forms of protest that zines make possible. Although critiques of labor are a common theme in zines, they also require extensive labor to produce. The handmade aesthetics emphasize the connection between the creators and their productrevealing the work of production in a way that the slickness of commercial media conceals [11]

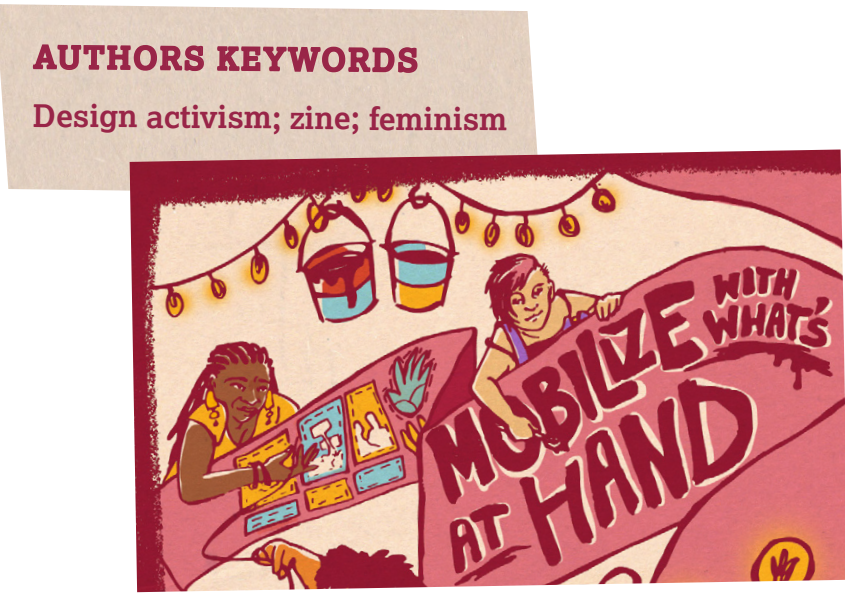

In this pictorial, we use the style of zines to make visible the work of transforming design culture-and the potential of design to participate in that transformation. We examine our own process of creating simple acts of resistance through interactive posters and buttons. Through building instruments of protest with members of our community, we discovered the importance of a particular approach to building called "lightweight design interactions." In these interactions, materials are lightweight in two senses. Literally, the materials have little heft or weight (e.g. paper, tape, fabric). Figuratively, the materials are lightweight in their preparation (readily available, inexpensive), in their assembly (easily drawn together), and in the skills required to use them (can be effective with no prior technical knowledge). In a series of gatherings, we offered opportunities to leverage the tools and methods of engagement of our university institutions (e.g., campus makerspace, a panel discussion) to reimagine these familiar forms as containers for new or different questions around what alternatives might be possible. 
When we bring our attention to our everyday environments, we begin to see the potentials for change that lie in sedimented social processes of ordinary life. For example, design and $\mathrm{HCI}$ research has considered the ways in which people design through incremental adjustment to their surrounding environments, from homes to parks to workplaces. Naming these practices "everyday design," scholars Audrey Desjardins and Ron Wakkary [10] examine seemingly mundane actions in collective spaces, such as an individual rearranging clutter on a family's kitchen counter. Taylor et al. show how such acts of adoption and reuse reflect simple, invisible forms of creativity that are often only noticeable to those doing the work [35]. A separate body of research has explored the development of design practices that aim for users to interact in lightweight ways [17]. By casting our attention to the seemingly ordinary interactions that surround us, we follow design scholar Sasha Costanza-Chock's call to "acknowledge the importance of everyday, vernacular, and often unrecognized design practices" [9:13]. This attention brings into view overlooked processes and participants that demonstrate how design can be done politically and in pursuit of justice.

Together our lightweight design engagements build on this work to highlight the value of drawing on the everyday materials and conditions of our institutional environments in formulating our interventions. Rather than speculating on hopeful technological endeavors, our interventions sought to create intermittent and sometimes imperceptible changes that augment or contend existing structures - from the staging of an academic panel to rival another to the collective production of posters to fill the lack of administrative response to on-campus violence. We acted within departments and labs that prize creation and innovation to become "inventive" in the way suggested by feminist scholar Sara Ahmed: through claiming space, time and materials for speaking out [1].

The Wages for Housework movement positioned acts of everyday domestic labor as a site for political struggle. It contested the reliance of capitalist economies on exploiting unpaid caregiving and housework (e.g., cooking, cleaning, and child care) that are essential for living.
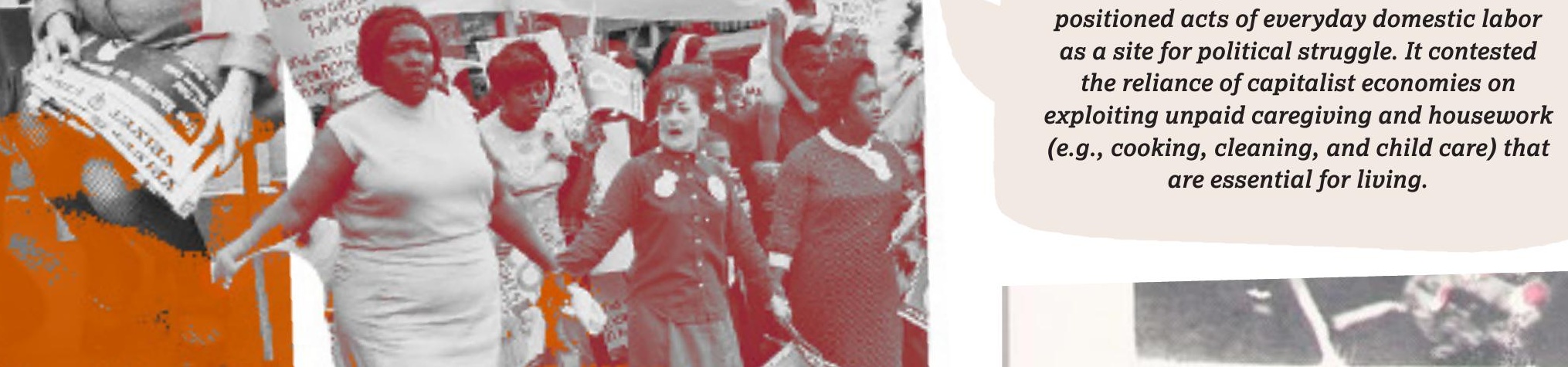


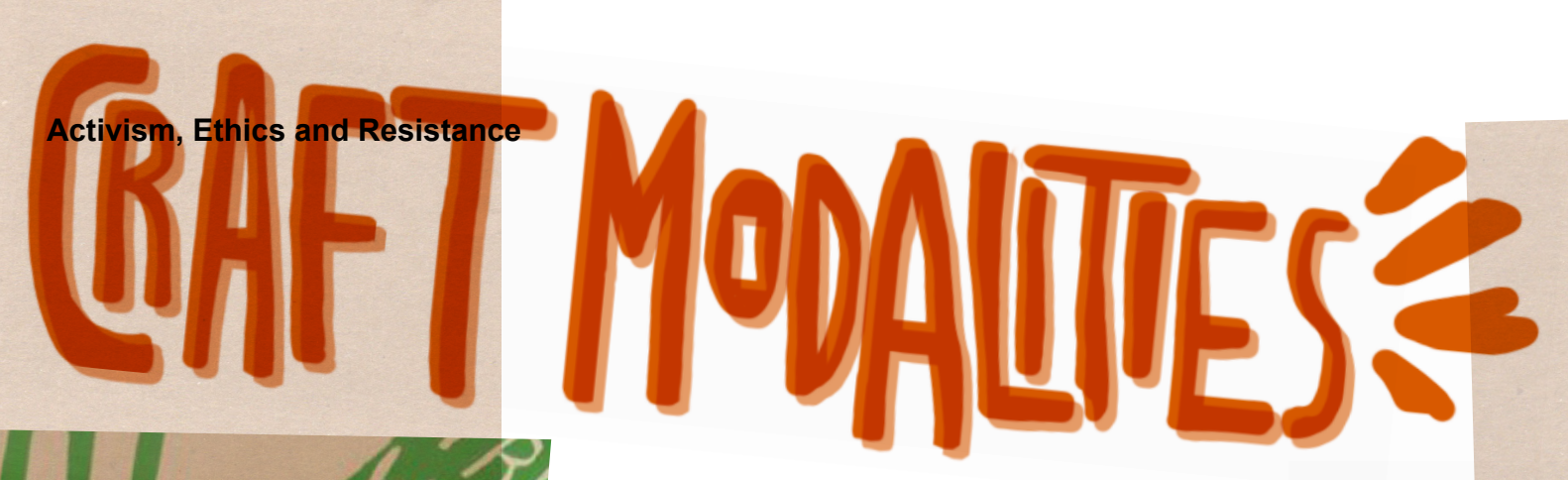

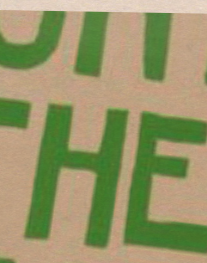

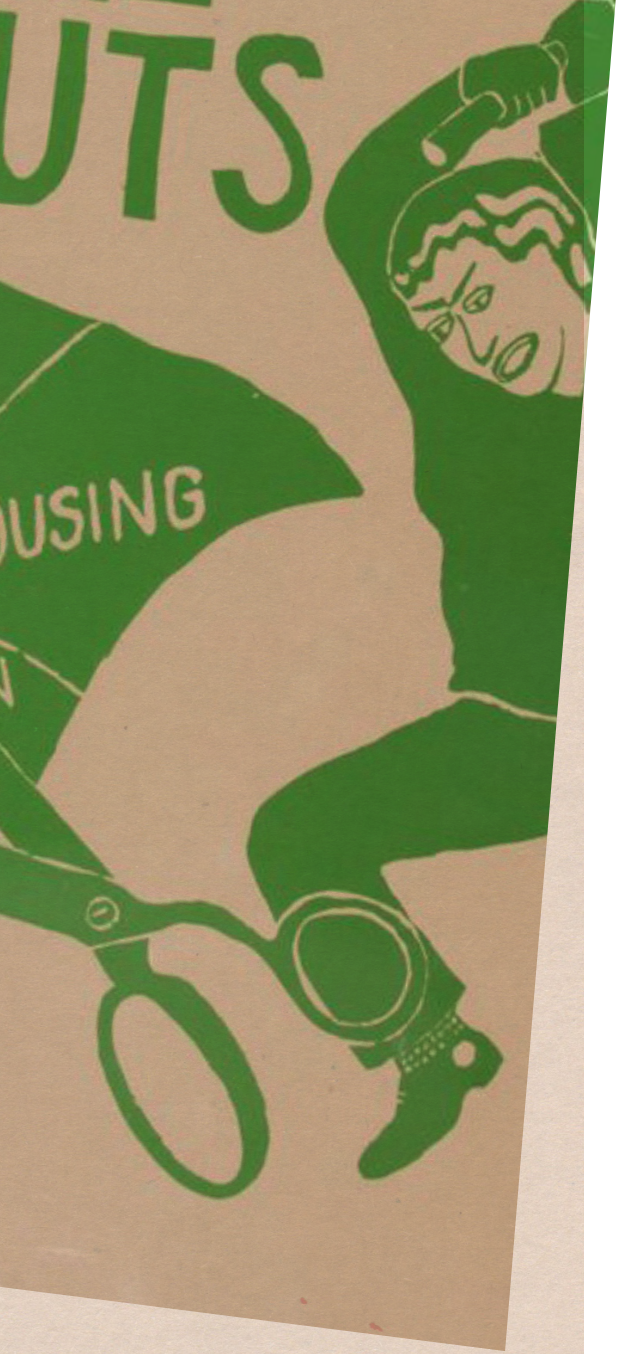

Through craft, we have a certain way of being with each other. Anyone who has knitted, quilted, scrapbooked, or painted with others has felt the way that our focus on doing gives way to talking; starting and stopping; intimate, as if the movement of your hands distract you just enough to overcome the hesitation that limits regular conversation. The recent resurgence of "stitch-n-bitch" knitting circles highlights the way that creative practice also opens space for complaint. Artists and activists mobilize this entwining of social critique and creativity in the form of "craftivism." As a mode of "gentle protest," craftivism counters the accusatory eruptions of traditional protest with a quiet consideration of how we are all involved in the problems of injustice and the solutions [8].

Within HCI, scholar Matt Ratto discusses the capacity of material engagement to inspire critique and reflection [25]. For Ratto, this practice of "critical making" is useful for reflecting on the role of technology in society - ultimately inspiring technology creators to feel a sense of responsibility for their impact on the world. Our engagements took a slightly different viewpoint: offering making as a method of slightly different viewpoint: offering mith others. It takes these inner reflection and communion with others. It takes these feelings and explorations as a potential starting place for political action, as "a spawning ground for the most radical and daring of ideas," in the words of poet and activist Audre Lorde [20]. Lightweight design interactions provide the material elements for expressing and reconsidering the multiple, contradictory feelings that are inherent in times of trouble. In making the objects of protest, we made visible our wonderings and discontents - and, perhaps more importantly, gathered with one another to produce and deploy them.
For example, CheyOnna Sewell and The Yarn Mission have used public acts of knitting to spark conversation between strangers about racial profiling and police brutality [18,27]. Elsewhere, Liza Stark and Nicole Messier integrate protest messaging and textiles with soft circuits and electronics in projects they call "e-craftivism" [28]. 


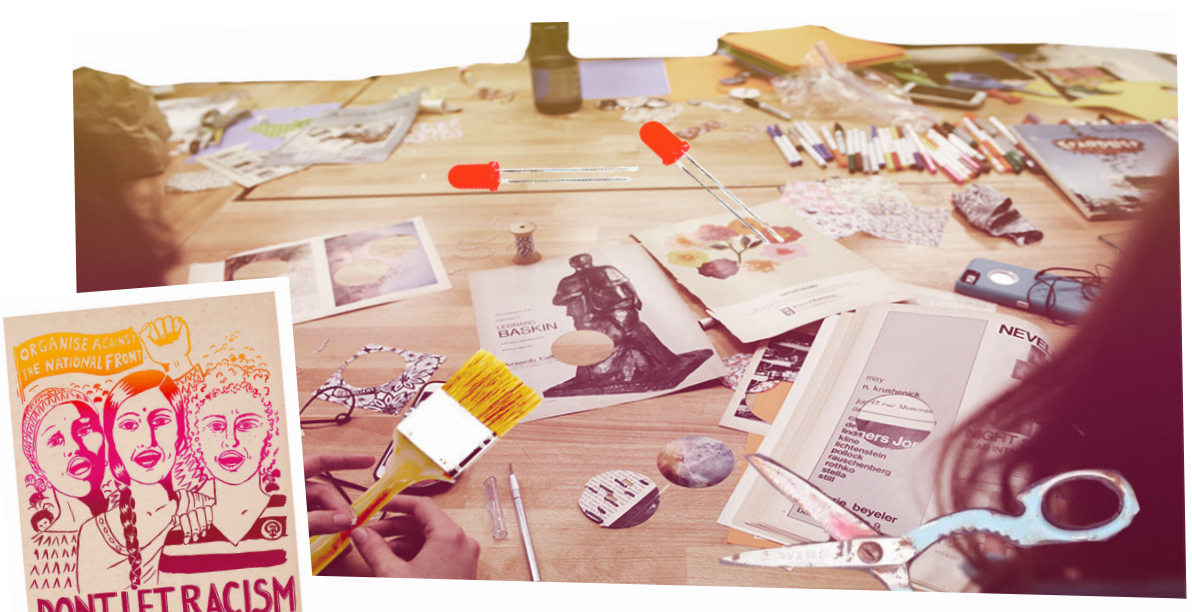

\section{DONTIETRACISM} GT DIVIDE US
As we collected ourselves after the 2016 U.S. election, we sought to join in emerging efforts of resistance. Gathered around a table in Rosner's kitchen, we reviewed feminist movements of the past and read over the newly published demands of the Women's March, a nationwide action held on January 21, 2017 that was later estimated as the largest single-day protest in recorded U.S. history [7]. While the movement later faced national controversies and financial struggles, the 2017 march has been widely regarded as "the moment the 'resistance' was born" [22]: expressing solidarity with those who have been threatened because of their faith, immigration status, race or ethnicity, sexual orientation or gender identity [34]. We sought to contribute to this flourishing multi-city movement through our own local means of production.

Our workshop series began with a set of supplies that were everyday, inexpensive and left-over from other projects. The shelves of our design lab held tupperware bins overflowing with sharpies and conductive paints, and tiny drawers packed with LEDs, wires, and googly eyes. We'd used these materials for prototyping and participatory workshops, but they could also be used for protest.

We were inspired by lineages of craft-based expression that used lightweight materials as the starting point for making bold political statements rooted in personal experience. See Red Women's Workshop, for instance, critiqued sexism through stencils and screen prints because they could be made using "the minimum equipment" [29]. Adopting these poster making processes would allow us to make multiple signs using only a few tools, a single screen, and to share graphics with others.
Alicia, a high school student and gender justice advocate, carefully cut the outline of a pair of underwear that read "my business," and described a "pad bombing" she'd recently organized with her classmates. They'd tucked messages about queer history and reproductive health into menstrual pads and stuck the adhesive backing to the hallways of their school. The posters, she explained, were meant to signify solidarity as she printed copies for each of her co-conspirators.

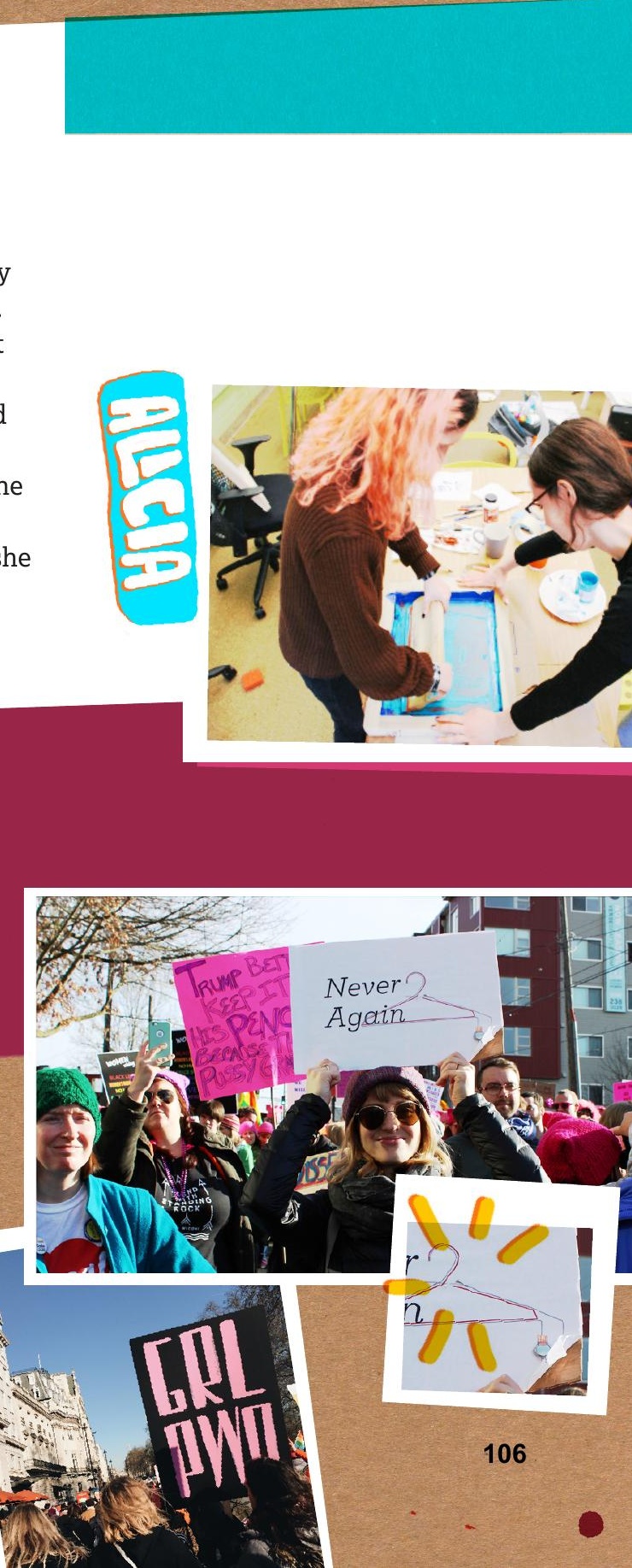

Another community member crafted a poster stating definitively, "Black Trans Women Matter" in minimalist, bold type.

Our posters used conductive inks and LEDs to light up our messages against the drizzly Seattle winter sky. At the march, our campus community began to express their political concerns creatively and collectively. 


\section{Activism, Ethics and Resistance -LIGHTWEIGHT PREPARATION}

Much like drawing on the material resources that surrounded us, our colleagues organized knowledge and expertise from around the campus community to field opposition to hateful speech.
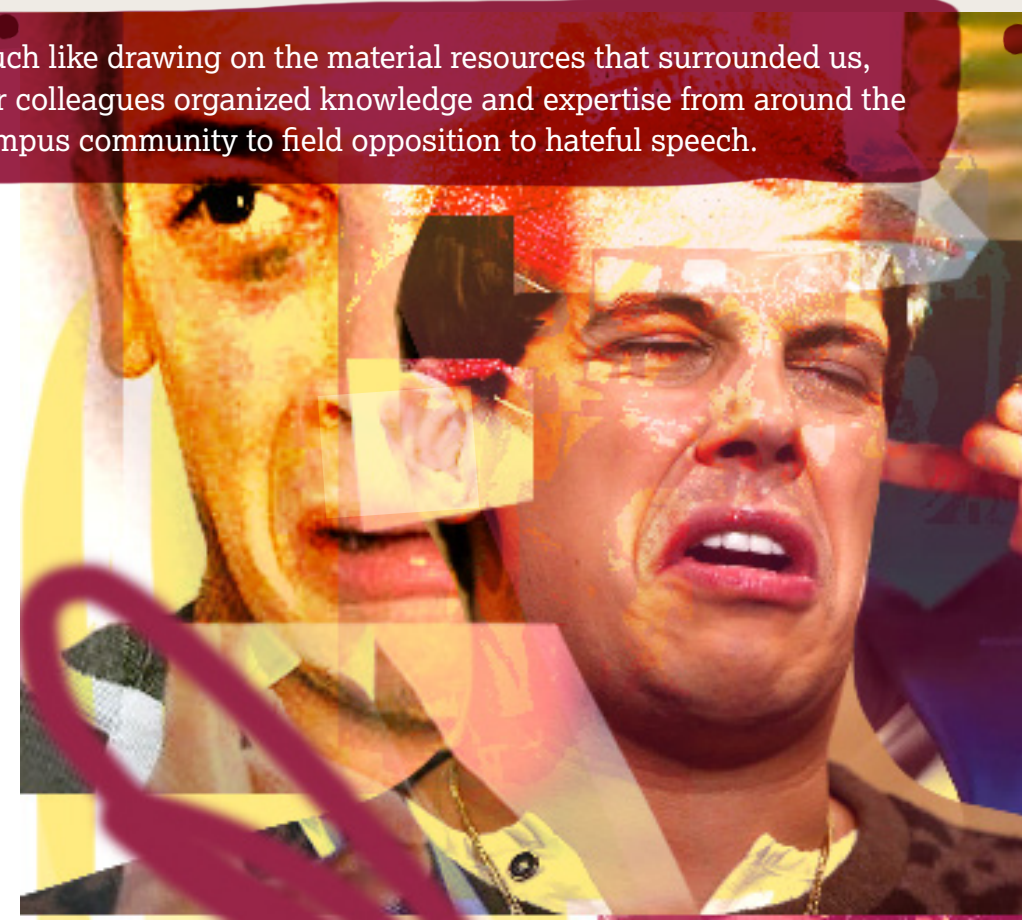

0
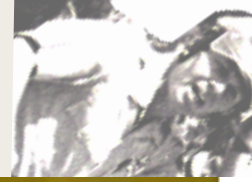

(1)

P (av

We saw physical lightweightness in the design of protest artifacts such as posters, but how did it work as a means of political action beyond things? Lightweightness asks us to draw on the everyday resources that surround us, and often those resources are people and relationships. As it happened, we witnessed an example of lightweightness in preparation as our campus responded to verbal and physical violence.

Our activities creating the posters for the Women's March unfolded under a looming campus visit from alt right extremist Milo Yiannopoulos. As the night unfolded, violence broke out as an attendee shot and injured an activist blocking entry into the lecture hall. Prior to his visit, members of the campus community feared Milo Yiannopoulos' speaking engagement would legitimize and encourage political views that the university president publicly identified as "repulsive." Yiannopoulos' divisive opinions directly addressed design and engineering communities. On a far-right commentary website, Yiannopoulos called for a cap on women enrolling in science majors - citing the disproportionately high number of women who receive science degrees but don't go on to work in scientific fields [24]. This phenomenon - often called "The Leaky Pipeline" - is concerning for educators across the political spectrum who call for correcting hostile environments that deter women's participation [16]. Yiannopoulos instead finds fault in women who "can't cope" in results-driven fields.
DIS '20, July 6-10, 2020, Eindhoven, Netherlands

In response, an attendee of the screen printing workshop worked with professors in the Computer Science and Engineering department to prepare a familiar organizational form as a lightweight means of resistance: the academic panel. Titled "Frontiers of Science and Engineering" and scheduled for the afternoon preceding Yiannopoulos' talk, the panel consisted of nine women working in science to challenge the idea that women aren't contributors to scientific fields. Women are there, even when they aren't called on, cited, tenured, or listened to. The panel instantiated a lived counterargument.

Notably, according to a panelist, two male professors in the Computer Science department did much of the preparation for the event. This is precisely the sort of service labor that is often shouldered by those already marginalized within academia [23], but -in this case - a subtle but powerful inversion meant sourcing and elevating the knowledge of those whom Yiannopoulos and his followers argued shouldn't be present at all.

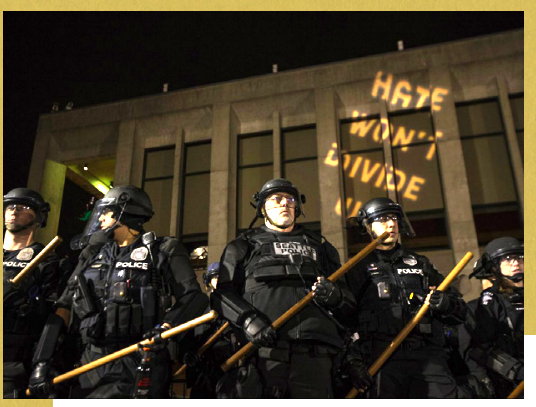

\section{FRONTIERS}

OF

\section{SCIENCE}

In our campus lab, we put the finishing touches on our posters for the march the next day. Milo devotees, Antifa protesters, curious students, and reporters passed underneath our third floor window to congregate in the nearby square. Helicopters circled overhead and police waited in riot gear.
The descriptions of the panel intentionally didn't include references to gender, in order draw attendance from hose uninterested in diversity.

\section{$\delta$}

\section{ENGINEERING}

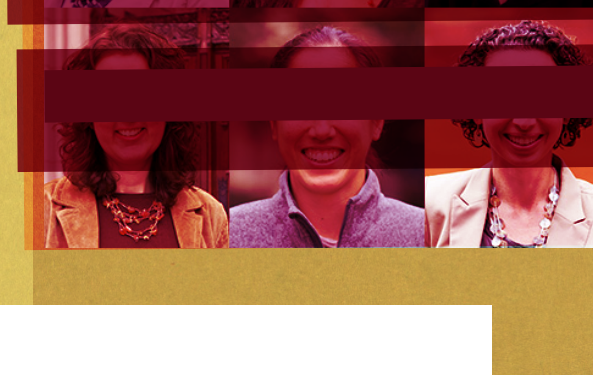




\section{ASSEMBLY}

We had already gathered the materials: chipboard, rolls of poster paper, silk screens, and sheets of craft plastic. Through the March, we learned we

Through the ongoingness of our encounters, we formed alliances with those across Trew on a similar set of material practices each institutional units and positions of the activities. time, creating opportunities for collective learing relationships, we had the resources to Once we began to gather materials and build relationships, we had the respond. quickly draw on when entrenched university structures struggled to respond.

\section{BNOT PANIC}
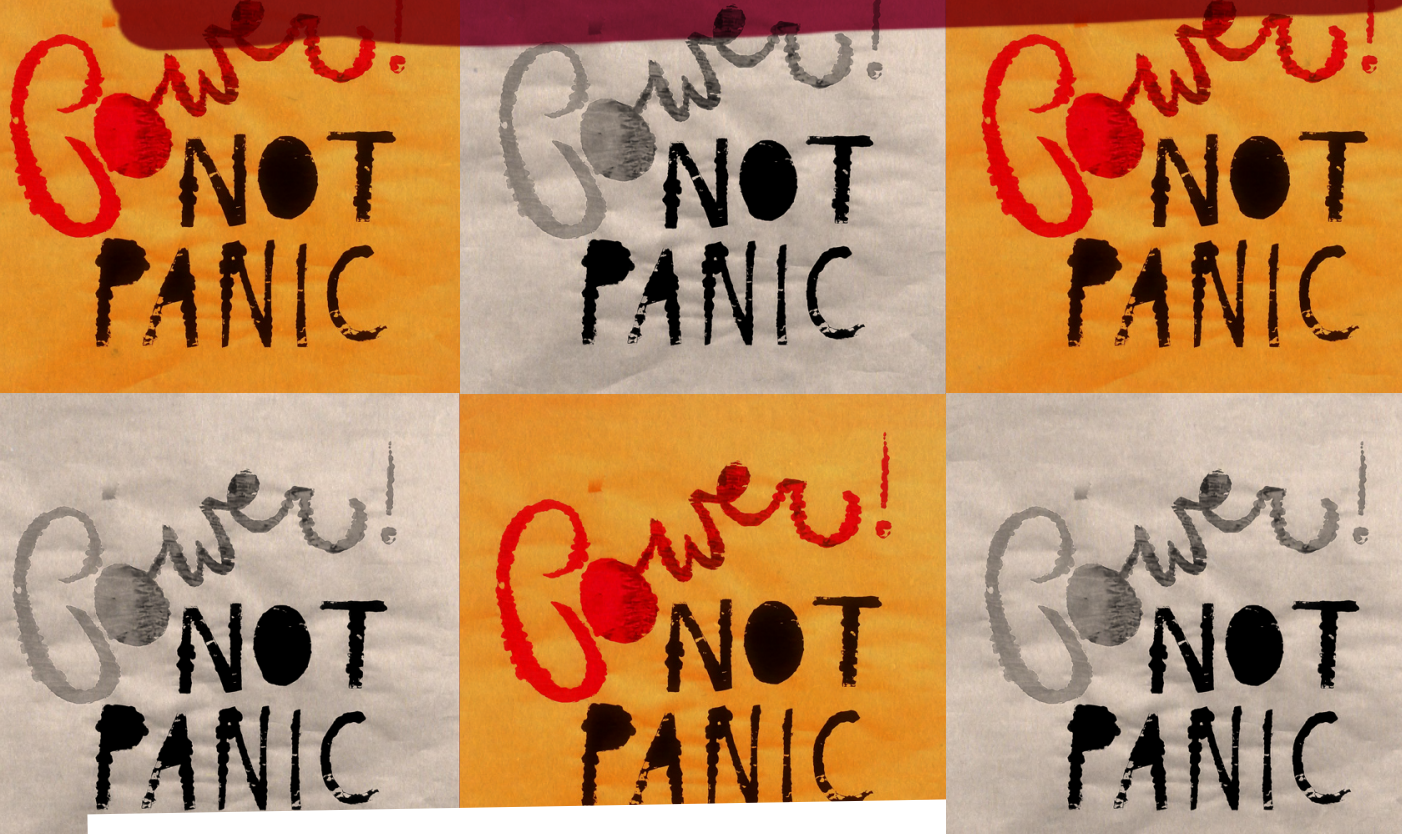

In the weeks that followed the Yiannopoulos speech, fear and distrust pervaded the campus community. We followed news out of nearby University of California, Berkeley, where another scheduled Yiannopoulos appearance had sparked additional violence [10].

Alongside this, in the dead of night in late January, a Neo-Nazi group descended upon campus plastering buildings with anti-semetic, homophobic, sexist, and ableist signs and graffiti, simultaneously seeking to recruit some and intimidate the rest of our community. We became increasingly disturbed by our administration's lack of response in the days that followed, turning instead to our own evolving program of questioning and refusal. could use these things to make a

statement. Our initial poster making created a repertoire of practices for us to draw on, now we began assembling alliances between members of our community.

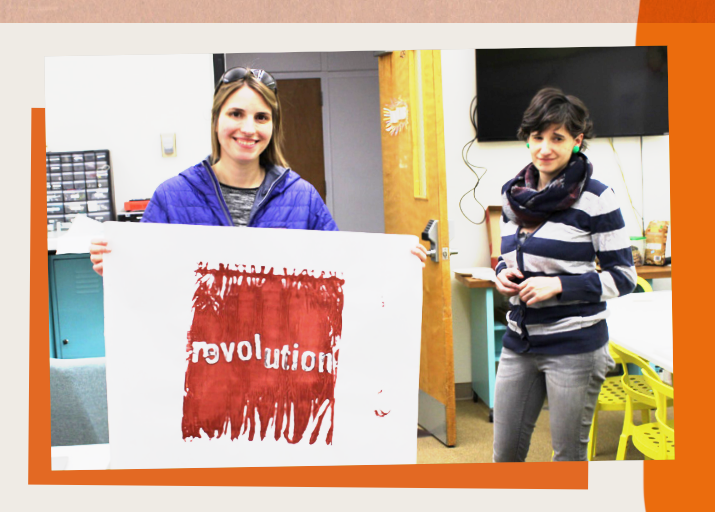
Engineering building, we gathered for two hours with an expanding group of students, professors, and staff from across campus. A faculty member used an exacto knife to carefully cut the words "Revolution" from a sheet of clear acetate. Half way through painting the letters, she flipped the stencil-emphasizing love at

An administrator who worked in a building that was targeted during the Nazi campaign coordinated an effort with fellow staff to design shirts printed with the phrase, "No Hate No Fear." They planned to wear them together to a campus town hall the following week, signalling a definitive rejection of the violence witnessed across campus and an artful critique of the silence from the university higher ups.

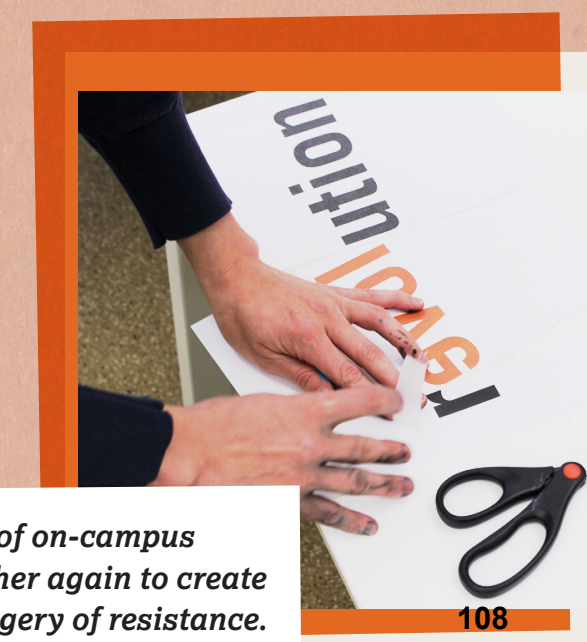




\section{IIGHTWEIGHT SKILLS} impetus for us to continue engaging creative practices - this time through button were encouraged by the enthusiasm and originality of the poster makers. Yet, as researchers, we also wanted to engage in conversations about artistic strategies to address systems of oppression.

Visual symbols of activism, such as the red ribbon created by Visual AIDS [33], have a powerful history of heightening awareness in situations where silence from those in power has perpetrated violence and death. Yet critiques of recent symbols of solidarity, such as safety pins and pink pussy hats, have pointed out that simply pinning a badge on your sweater is among the easiest forms of allyship and does little to challenge dominance patterns such as white supremacy [16]. What were the possibilities and limits of making as a means of feminist resistance?
The collective purpose we felt through the poster making sessions was an making at our campus makerspace. As members of the campus community, we

Joanie, a medical student and activist, created a button in which a cloaked woman peered-out from behind two drapes she'd created from scraps. At the end of the workshop Joanie described her ambivalent relationship to softness (symbolized through the fabric) in both lines of her work. She didn't want to fulfill gendered expectations that women are supposed to be tender. But, at the same time, she found power in it, as the softness attuned her to other's perspectives and needs.

As Joanie's story illustrates, creating the materials of dissent can create opportunities for reflection and considering one's stance.

Rather than seeking an immediate solution for social problems, the lightweight design interaction was a means to sit with the contradictions and challenges that are present in the intersecting experiences of being a woman, a worker, an activist and a caretaker. Joanie could claim the tenderness that she hoped to cultivate.

We gathered the materials from the poster-making sessions and brought them to the campus makerspace, a "collaborative innovation hub." It's typically filled with students and start-up employees who prototype with a wide variety of tools — from 3D printers to sewing machines.

The workshop attendees were invited to begin button making with stacks of vintage magazines, glue sticks, scissors, and felt tip pens. Drawing on the pastiche aesthetics of zines and collage, attendees used these materials and their existing skills to express commentary and commitments. The intricate, original images they created were pressed into buttons by a group of participants who collected around an analog button press. Once pressed, attendees added circuitry made of copper tape and LED stickers to their buttons as another layer of collage.

The button making workshop leveraged lightweight skills by drawing together paperbased craft and basic electronics, presenting them as sharing the same underlying practice (collage). Skills for creative expression and skills for technology were entwined to become skills for resistance.

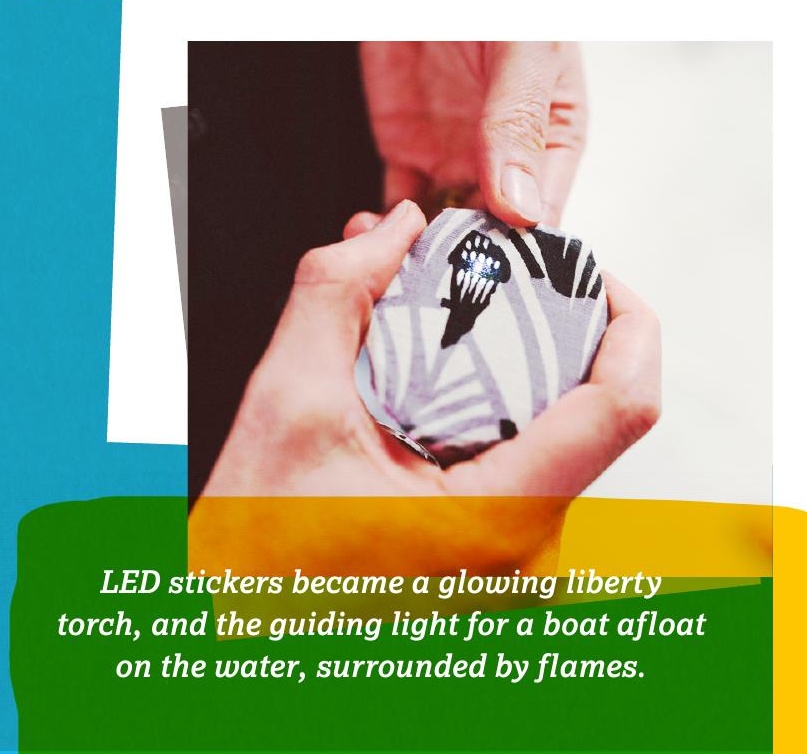

tede

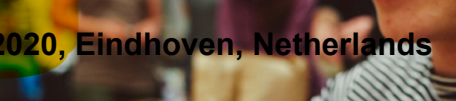

, Eindhove
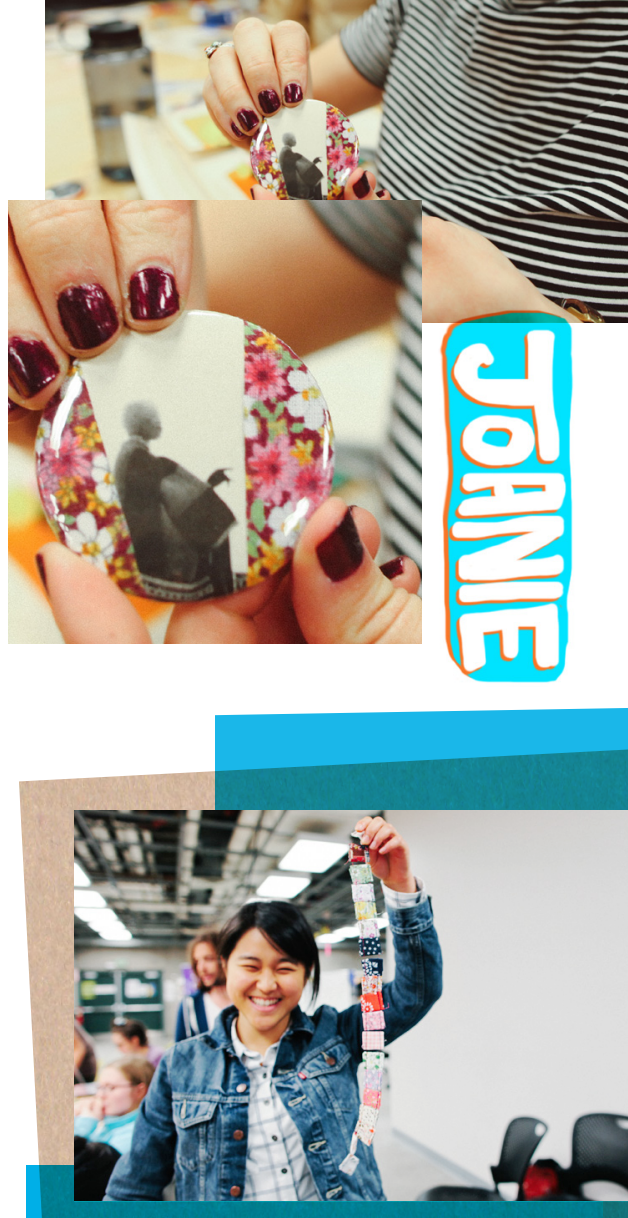

Fabric also served a technical function. A team of women sewed 1 -inch pockets to insulate the circuit batteries from the metal backing of the buttons.

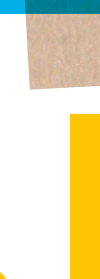

Feminist, queer, and zine makers of color have integrated methods of collage with craft materials to create new visual narratives and to theorize their lived experience [24]. 
ZIN E S and screen prints are methods of expression that are relatively easy to

reproduce and circulate. This page - an original design by Spektor - offers itself as a

stand alone, take-away image that can be hung in offices or dorms as a statement in itself.

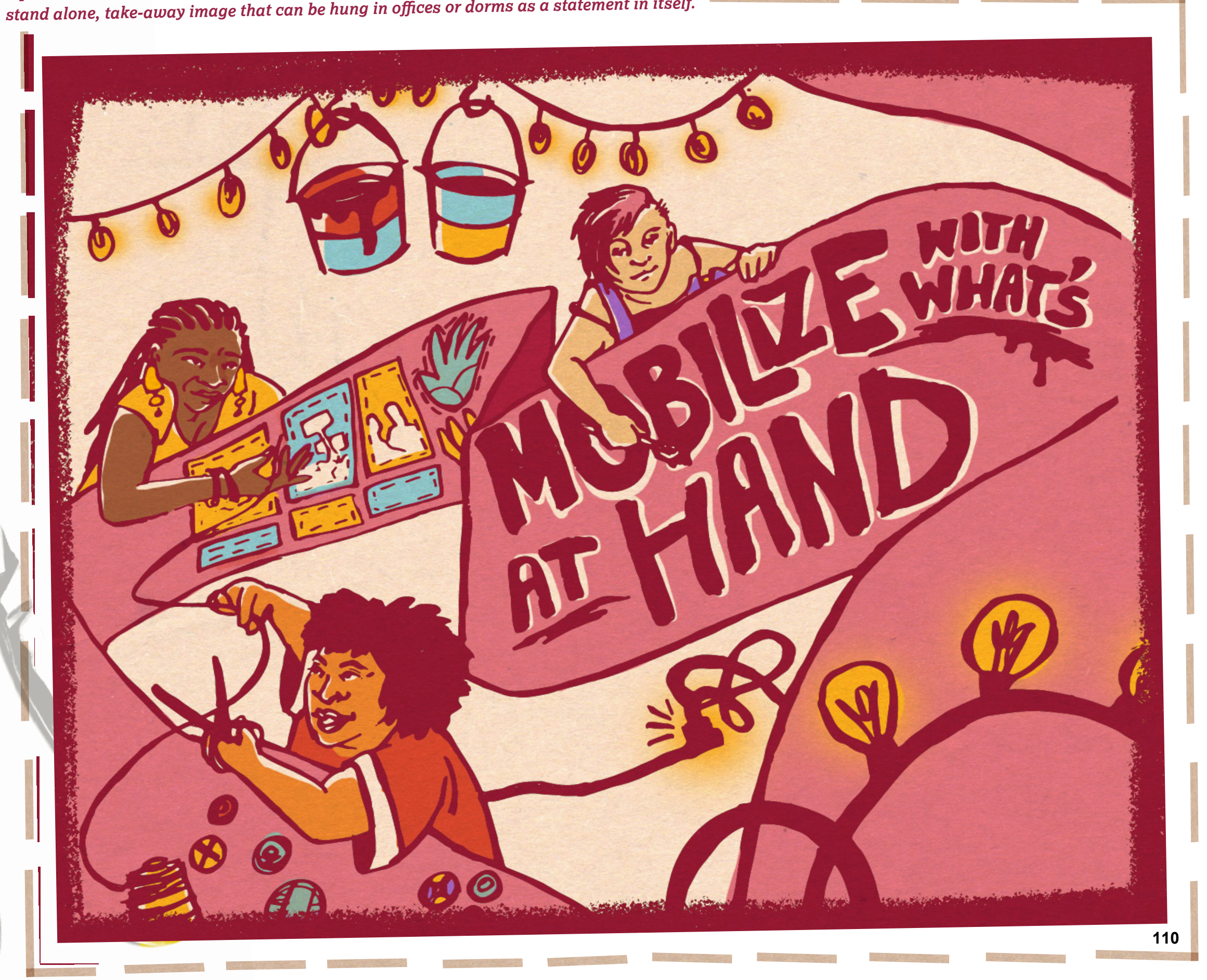




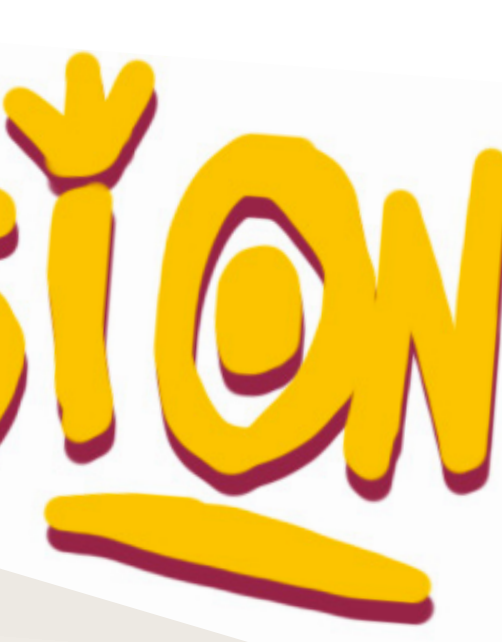

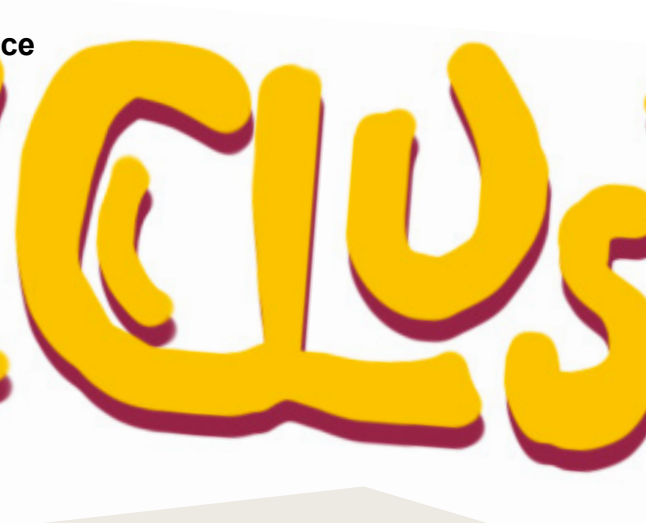

\section{(.)}

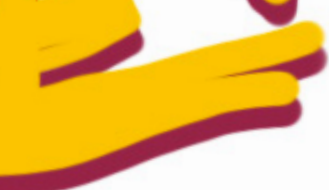

As the above reflections on our workshop illustrate, gathering together to make objects of public protest becomes a pathway for conversation and solidarity. The technical concepts engaged in the design process may have been lightweight. But, in the acts of joint creation, we thought deeply with one another, we built new connections and introduced subtle frictions into a political progression in our immediate environment that could have continued unquestioned. The administrator who designed the No Hate No Fear" t-shirt, for example, went on to organize a protest with other office workers during a town hall with university officials. Similarly, Alicia later distributed screen printed signs to her fellow classmates who demanded for their bodily autonomy to be recognized by their parents and principals alike. Our ephemeral actions together rippled outward into our communities.

In 1979, Audre Lorde famously declared that "the master's tools will never dismantle the master's house" [24]. Today, commentators have been fond of exploring this statement to ask whether the technologies built in corporate settings - to accrue power, money, and personal data - can be used for other, more equitable, means [36]. When taken as a single line, Lorde's statement offers itself seductively to activists and technology-faithfuls alike. Much like the "making-do" suggested by de Certeau [6], could we use the materials (the literal tools: computers and capacitors) to organize, claim, and build a more just future? However, Lorde's declaration has little to do with artifacts and everything to do with the social structures of oppression.
This realization pushes feminists and activists of all kinds to acknowledge that lightweight design interactions are an opportunity for building certain kinds of relationships. Our knowledge, our colleagues, and the materials living in the back of lab cabinets all continue to be resources for reshaping our academic design communities. With this abundance comes a responsibility to respond with what we have at hand, to-in the words of Asad et al.-become "academic accomplices" [2]. Lightweight design interactions are creative acts that must be collective, that must engage and coordinate multiple locales and bodies. In this collectivity, they suggest we continue to make the firm but lightweight steps that build the conditions in which different

futures take hold.

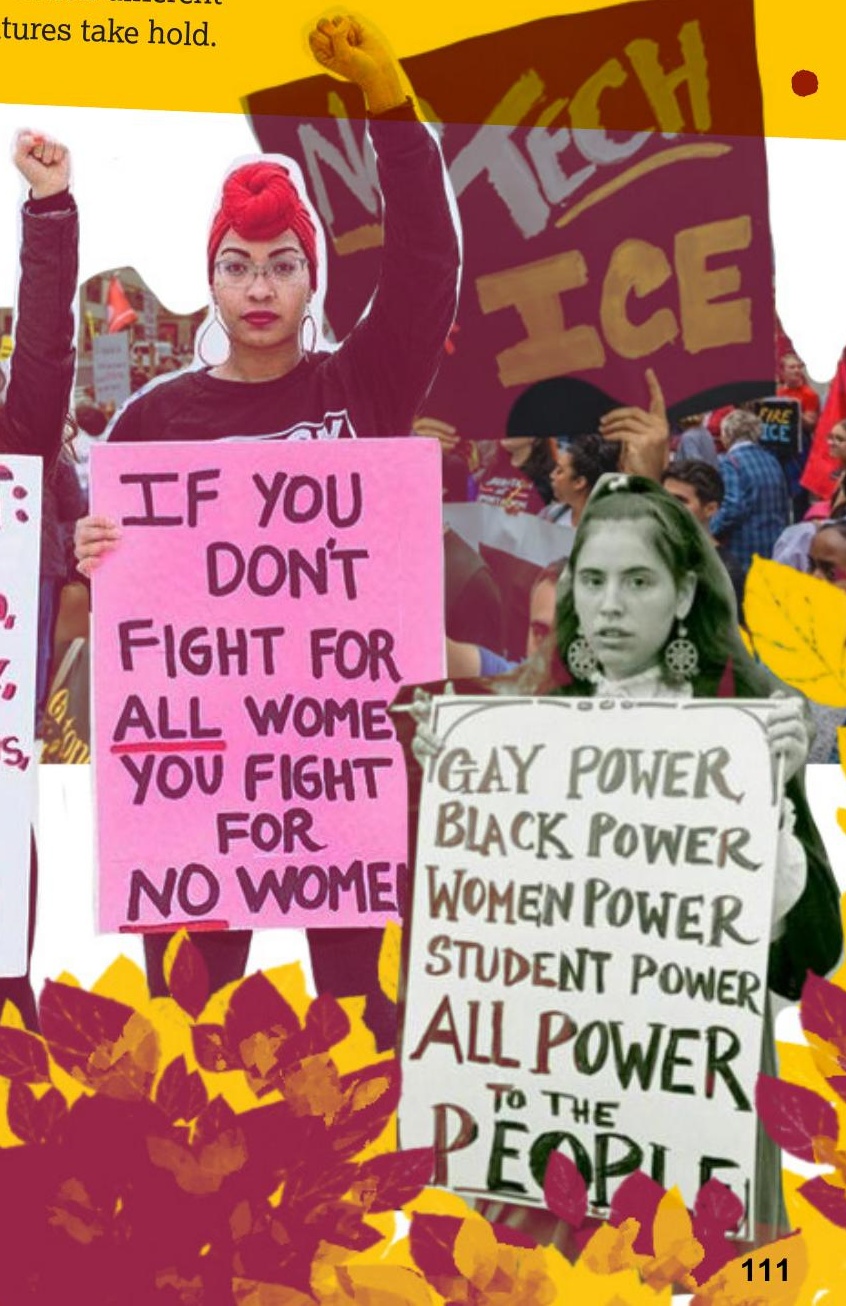




\section{ACKNOWLEDGMENTS}

We thank our fellow community members who gathered with us, members of the Tactile and Tactical Design Lab at the University of Washington, and our anonymous reviewers for their invaluable comments on this pictorial. This work was made possible in part by the support of NSF grants \#1453329, \#1423074, and \#1523579.

\section{REFERENCES}

[1] Sara Ahmed. 2017. Living a feminist life. Duke University Press, Durham, NC.

[2] Mariam Asad, Lynn Dombrowski, Sasha CostanzaChock, Sheena Erete, and Christina Harrington. 2019. Academic Accomplices: Practical Strategies for Research Justice. Companion Publication of the 2019 on Designing Interactive Systems Conference 2019 Companion, Association for Computing Machinery, 353-356.

[3] Melanie Ramdarshan Bold. 2017. Why Diverse Zines Matter: A Case Study of the People of Color Zines Project. Publishing Research Quarterly 33, 3: 215-228.

[4] Amy Burek, Emily Alden Foster, Sarah Fox, and Daniela K. Rosner. Feminist Hackerspaces: Hacking Culture, Not Devices (the zine!). In Making Things and Drawing Boundaries: Debates in the Digital Humanities.

[5] Sara Century. 2017. 'They Bring Activism To A New Level': A Female Zinesters Roundtable. Medium. Retrieved January 28, 2020 from https://medium.com/ the-establishment/the-power-of-zines-and-the-womenmaking-them-c8736bf0947d.

[6] Michel de Certeau. 1988. The practice of everyday life. University of California Press, Berkeley, CA.
[7] Erica Chenoweth and Jeremy Pressman. This is what we learned by counting the women's marches. Washington Post. Retrieved January 28, 2020 from https://www.washingtonpost.com/news/monkey-cage/ wp/2017/02/07/this-is-what-we-learned-by-countingthe-womens-marches/.

[8] Sarah Corbett. 2018. How to be a craftivist: the art of gentle protest. Random House, London.

[9] Sasha Costanza-Chock. 2020. Design Justice: Community-Led Practices to Build the Worlds We Need. MIT Press, Cambridge, Massachusetts.

[10] Audrey Desjardins and Ron Wakkary. 2013. Manifestations of everyday design: guiding goals and motivations. ACM, 253-262.

11] James Doubek. 2017. Breitbart Editor's Event Canceled As Protests Turn Violent At UC Berkeley. The Two Way. Retrieved January 20, 2020 from https://www.npr.org/sections/thetwoway/2017/02/02/512992000/breitbart-editors-eventcanceled-as-protests-turn-violent-at-uc-berkeley.

[12] Stephen Duncombe. 1997. Notes from underground: zines and the politics of alternative culture. Verso, London.

13] John Fiske. 1992. Cultural studies and the culture of everyday life. In L. Grossberg, C. Nelson, and P.A. Treichler, eds., Cultural studies. Routledge, New York.

[14] Sarah E. Fox, Catherine Lim, Tad Hirsch, and Daniela K. Rosner. 2020. Accounting for Design Activism: On the Positionality and Politics of Designerly Intervention. Design Issues 36, 1: 5-18.

[15] Sarah Fox and Daniela Rosner. 2016. Continuing the dialogue: bringing research accounts back into the field. ACM, 1426-1430.

[16] Lauren Kaori Gurley. 2019. A Fired Kickstarter Organizer Is Trying to Unionize Tech Workers Using Kickstarter. Vice. Retrieved January 28, 2020 from https://www.vice.com/en_us/article/d3aqkz/a-firedkickstarter-organizer-is-trying-to-unionize-techworkers-using-kickstarter.

[17] Richard Harper. 2010. Texture: human expression in the age of communications overload. MIT Press, Cambridge, Massachusetts.

[18] Derek Hawkins. 2017. Safety pins: Solidarity symbol or emblem of 'white guilt'? Washington Post. Retrieved January 20, 2020 from https:// www.washingtonpost.com/news/morning-mix/ wp/2016/11/15/safety-pins-solidarity-symbol-oremblem-of-white-guilt/. 


\section{REFERENCES}

[19] Sarah Homewood. 2019. Inaction as a Design Decision: Reflections on Not Designing Self-Tracking Tools for Menopause. Extended Abstracts of the 2019 CHI Conference on Human Factors in Computing Systems, Association for Computing Machinery, 1-12.

[20] Noura Howell. 2018. Participatory Peace Sculpture.

[21] Sarah Kendzior. 2015. Ferguson's radical knitters: "If someone asks me what I'm doing, I say, 'I'm knitting for black liberation." The Guardian. Retrieved January 20, 2020 from https://www.theguardian.com/ us-news/2015/aug/06/ferguson-radical-knitters-talkjustice-race-issues.

[22] Jason Lazarus. 2011. Phase 1 Live Archive.

[23] Audre Lorde. 2018. Poetry is not a luxury. In The master's tools will never dismantle the master's house. Penguin Books, London, 1-5.

[24] Audre Lorde. 2018. The master's tools will never dismantle the master's house. Penguin Books, London.

[25] Mike Enright. 2020. 'Nobody needs another pink hat': Why the Women's March is struggling for relevance. The Washington Post. Retrieved January 28, 2020 from https://www.washingtonpost.com/.

[26] Joya Misra, Jennifer Hickes Lundquist, Elissa Holmes, and Stephanie Agiomavritis. 2016. The Ivory Ceiling of Service Work. American Association of University Professors. Retrieved January 20, 2020 from https://www.aaup.org/article/ivory-ceilingservice-work?wbc_purpose=basic\&WBCMODE=prese ntationunpublished\#.XiXwQFNKgUs.

[27] Alison Piepmeier. 2009. Girl Zines: Making Media, Doing Feminism. NYU Press.

[28] James Pierce. 2012. Undesigning technology: considering the negation of design by design.

Proceedings of the SIGCHI Conference on Human Factors in Computing Systems, Association for
Computing Machinery, 957-966.

[29] Matt Ratto. 2011. Critical making: Conceptual and material studies in technology and social life. The Information Society 27, 4: 252-260.

[30] Reshma Saujani and Ayah Bdeir. You Can't Solve The Gender Gap In Tech If You Don't Understand Why It Exists. Retrieved September 24, 2019 from https://www.buzzfeednews.com/article/ reshmasaujani/tech-gender-gap-pipeline-myth.

[31] CheyOnna Sewell. 2016. Racial justice and the role of knitting. Retrieved January 18, 2020 from https://theyarnmission.com/ mwccreflectionandtranscript/.

[32] Samantha Shorey, Sarah Fox, and Kristin Dew. 2017. Glimmers and half-built projects. interactions 24, 6: 78-81.

[33] Liza Stark and Nicole Messier. 2017. Crafting Resistance. Retrieved January 20, 2020 from http:// thesoftcircuiteer.net/projects/crafting-resistance/.

[34] Prue Stevenson. 2016. See Red Women's Workshop: feminist posters 1974-1990. Four Corners Books, London.

[35] Alex Taylor and Laurel Swan. 2005. Artful systems in the home. ACM, 641-650.

[36] Milo Yiannopoulos. 2015. Here's Why There Ought to Be a Cap on Women Studying Science and Maths. Breitbart. Retrieved January 20, 2020 from https://www.breitbart.com/politics/2015/06/15/hereswhy-there-ought-to-be-a-cap-on-women-studyingscience-and-maths/.

[37] 99 Percent Invisible. 2015. Awareness. Retrieved from https://99percentinvisible.org/episode/ awareness/.

[38] Mission \& Vision: Women's March on Washington. Women's March on Washington. Retrieved December 29, 2016 from https://www.

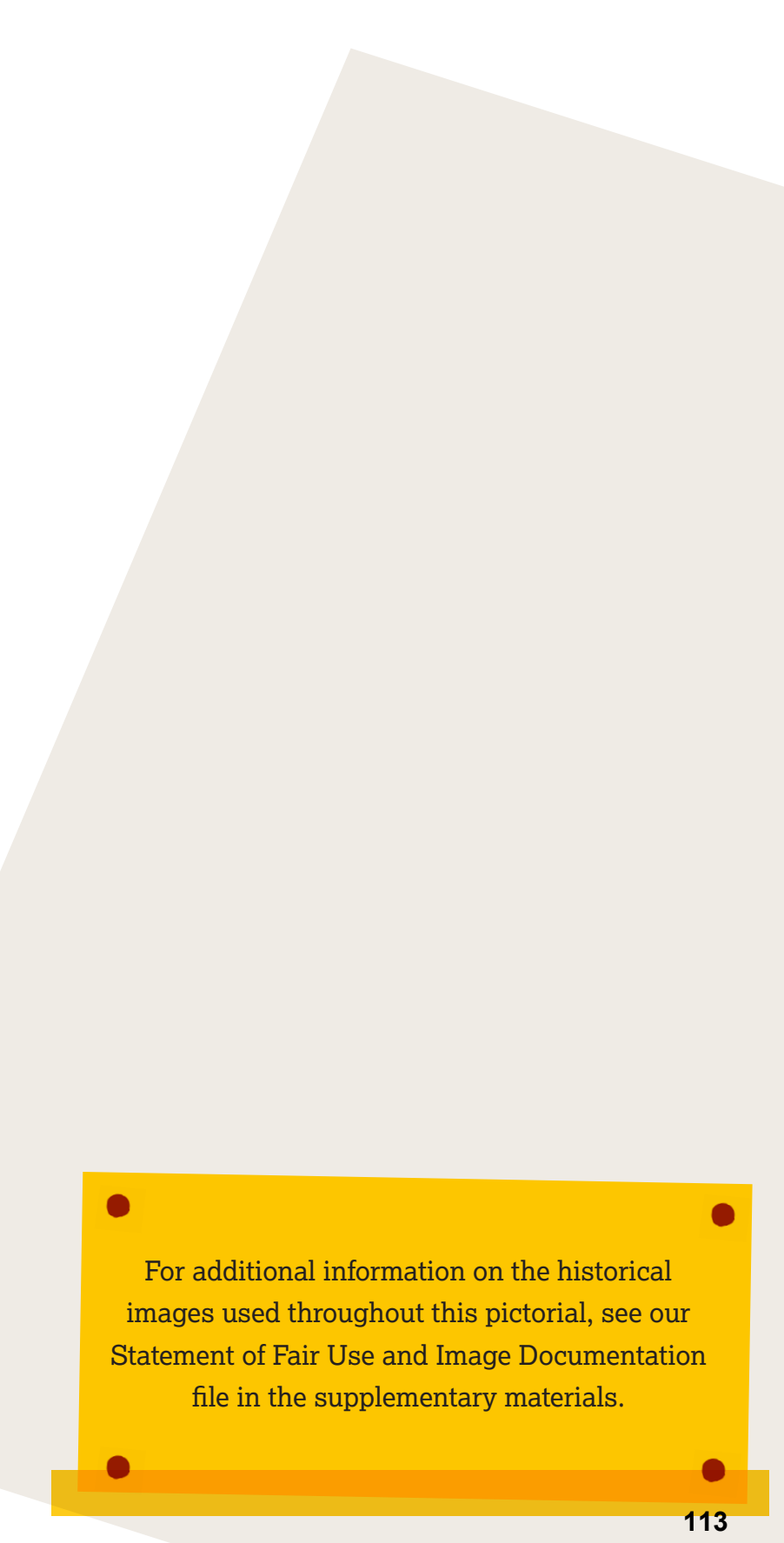

